\title{
The coping strategies followed by university students to mitigate the COVID-19 quarantine psychological impact
}

\author{
Ensaf Y. Almomani ${ }^{1}$ (I) $\cdot$ Ahmad M. Qablan ${ }^{2,3} \cdot$ Abbas M. Almomany $^{1} \cdot$ Fatin Y. Atrooz ${ }^{4}$ \\ Accepted: 5 May 2021 / Published online: 9 May 2021 \\ (C) The Author(s), under exclusive licence to Springer Science+Business Media, LLC, part of Springer Nature 2021
}

\begin{abstract}
Different strategies were followed to control the spread of the COVID-19 disease worldwide. Jordan declared a military-enforced curfew for three months, which successfully controlled the disease spreading. However, the curfew impacted several aspects of students' lives and personalities. This study discusses the impact of the COVID-19 curfew restrictions on university students' mental health, as this area was not fully discussed in previous studies. An online survey was distributed to cover the psychological symptoms and coping strategies of university students. Most of them experienced short temper, anxiety, and sleep problems. Female students expressed more psychological symptoms than males, they managed their stress by sleeping, studying, and worshiping. Whereas male students were working, exercising, and playing video games. A distinct interest was noticed among students of different ages. Young students (18-25 years) expressed unhappiness and distress-like symptoms; they advocated sleeping and playing video games. While elder students ( $>26$ years) had anxiety, sleep problems, and short tempers, they managed their symptoms by studying, exercising, and worshiping. The curfew restrictions have negatively impacted the mental health of female and younger students more than other categories. These research outcomes will help decision-makers to implement healthy coping strategies to be followed during unusual conditions.
\end{abstract}

Keywords COVID-19 $\cdot$ Curfew $\cdot$ University students $\cdot$ Jordan $\cdot$ Mental health

\section{Introduction}

Coronavirus disease 2019 (COVID-19) is a newly emerged infectious disease that affects mainly the respiratory system (CDC, 2020). It is a highly contagious disease that spreads by aerosols (Advice for the Public, n.d.) (Q. Li et al., 2020). The first infected case with COVID-19 disease in Jordan was recognized in early March 2020 (Ala'a B. Al-Tammemi, 2020). Later, the national defense law was declared to minimize the spread of COVID-19 disease in the country (COVID-19 Pandemic in Jordan, 2020) A military enforced quarantine

Ensaf Y. Almomani

e.almomani@zuj.edu.Jo

1 Department of Pharmacy, Alzaytoonah University of Jordan, Amman, Jordan

2 Department of Secondary Education, University of Alberta, Edmonton, Canada

3 Department of Curriculum and Instruction, Hashemite University, Zarqa, Jordan

4 Department of Pharmacological and Pharmaceutical Sciences, College of Pharmacy, University of Houston, Houston, TX, USA was put into effect for three months (Ala'a B. Al-Tammemi, 2020). Individual and car mobility were restricted. All entities in the country except hospitals and vital centers were closed (Ala'a B. Al-Tammemi, 2020). The curfew restrictions were effective in minimizing the number of infected individuals and deaths (Ministry of Health, the Official Website of the Jordanian Ministry of Health | Coronavirus Disease, n.d.), however it affected Jordanians' life routine and negatively impacted their mental health (Ala'a B. Al-Tammemi et al., 2020) (Naser et al., 2020).

Pandemics are usually associated with a high degree of stress resulting from fear of infection and death. Stress is amplified with the accelerated death rates among the COVID-19 patients. Several countries including Jordan followed the quarantine and the lockdown option in a step to control the disease spreading. Both the quarantine and the pandemic created a higher degree of stress among the population. A study from Italy showed that large group of people either expressed post-traumatic stress symptoms (PTSS), or suffered from depression, anxiety, and insomnia as a result of the quarantine (Rossi et al., 2020a).

The COVID-19 pandemic affected the general population's mental health. Amid the different population categories, 
the general practitioners' mental health was the most affected (Amerio et al., 2020) (D. K. T. Li \& Zhu, 2020). The general practitioners were at the frontline to deal with the COVID-19 infected people. They were susceptible to a high degree of stress and depression due to their direct responsibility for the wellbeing of the COVID-19 patients from one side and to the risk of infection from the other side. They expressed a high degree of depression and anxiety which affected their sleeping and quality of life (Amerio et al., 2020).

Studying university students' mental health during the pandemic is of growing importance. Among the several factors that affect the students' mental health comes the online learning platform. During the curfew, the university students had to stay at home and continue their education through an online learning platform, which they had never experienced before. There was an increase in the use of digital tools, and in the time spent on electronics after the COVID-19 pandemic compared to pre-pandemic use of this technologies (Haider \& Al-Salman, 2020). They also experienced electronic connection and accessibility problems during online learning (Almomani et al., 2021). This caused distraction and negatively impacted students' concentration abilities (Haider \& Al-Salman, 2020). The distance learning affected students' psychological state, most of them experienced anxiety, frustration, and depression during the pandemic (Haider \& AlSalman, 2020) (Ala'a B. Al-Tammemi et al., 2020) Naser et al., 2020). Different degrees of anxiety were noticed among university students during the pandemic with higher impact rates among female and younger students (Cao et al., 2020; Sundarasen et al., 2020). The students' social life was affected too, they became more isolated, and less energetic due to the prolonged home staying (Almomani et al., 2021; Haider \& Al-Salman, 2020).

The university students' mental health during the curfew was also influenced by the students' sensory perceptions. Students who may suffer from sensory processing disorder (SPD) were overly sensitive to stimuli that other people were not, due to their lower neurological threshold. This made them react differently during the pandemic (Serafini et al., 2017). The university students' sensory perception before and after the COVID -19 pandemic was not covered in this contest.

The focus of the previous studies was on measuring the distress and anxiety level of either the general population or for a specific group of students like medical college students (Sundarasen et al., 2020; Cao et al., 2020; Naser et al., 2020). They did not explore the strategies that students use to cope with their anxiety. Therefore, the goal of this study is to address the effect of the COVID-19 pandemic and the enforced quarantine on university students' mental health. It focuses on both the psychological symptoms and the coping strategies that students used during the quarantine to cope with the pandemic and its consequences. The study explores multiple variables related to university students such as area of study, level of education, and students' nationalities.

We hypothesized that university students' mental health could be affected by the COVID-19 quarantine practices that imposed into the students' life, therefore we assumed that students developed relevant coping strategies to deal with that disruption.

\section{Research Question}

This study tried to answer the following research questions:

1. What are the psychological symptoms that university students experienced during the curfew?

2. Is there any correlation between psychological symptoms and students' socio-demographics including; gender, age, field of study, academic year, type of studying program (graduate or undergraduate), origin of student (national or international), or status of living (with family or away from family)?

3. What are the coping strategies that university students practiced during the curfew?

4. Is there any statistically significant difference of those strategies on students based on their gender, age, field of study, academic year, type of studying program (graduate or undergraduate), the origin of student (national or international), and status of living (with family or without)?

\section{Methods}

\section{Population and Sample}

The population of this study included university students who were at least 18 years old of all majors in both public and private universities, with no exclusions of any response. The survey was announced to the entire population of university students all over Jordan without applying any restriction or exclusion to the students' demographic information like students' gender identity, their social representation, geographic location, rurality, ability, or socioeconomic status. The survey was published using google application forms, from May through Jun 2020. The number of respondents was 585 students and all the responses were included in the analysis. According to Jordan's Ministry of Higher Education and Scientific Research, there were 342,104 registered students in both public and private Jordanian universities for the academic year 2019. Out of the 585 participants, $372(63.6 \%)$ were female students. Most of the surveyors, $434(74.2 \%)$ were studying medical and pharmaceutical sciences, 96 (16.4\%) studying general sciences, 47 (8\%) studying engineering, and the rest $7(1.2 \%)$ were literacy and humanities 
majors. Most of the students were aged between 18 and 25 years. The surveyors were almost equally distributed among the first, second, third, and fourth academic years. Most of the surveyors, 553 (94.5\%) were enrolled in the undergraduate programs. Among the participants, there were $171(29.2 \%)$ international students who were studying in Jordan, and 228 (39\%) were studying and living away from their families during the curfew.

\section{Instrumentation}

The instrument used to collect data in this study was a two-part questionnaire. The first part collected demographic information related to student's gender, educational level, and field of study. The second part of the questionnaire included 20 items related to the psychological symptoms that university students experienced during the curfew as well as the coping strategies practiced by the students during the quarantine.

\section{Instrument Translation Process}

To ensure equivalence of meaning of the items and constructs between the Arabic and English versions of the questionnaire, a rigorous translation process was used that included forward and backward translation and subjective evaluations of the translated items (Sperber et al., 1994). The translation was done and edited by a bilingual university faculty member who participated in this research. The internal consistency of the instrument was calculated and yielded a Cronbach's alpha of 0.7. The questionnaire was then prepared in Google forms and the link was distributed to the official Facebook pages, and emailed to the academic staff to send to their students in several private and public Jordanian Universities. Data collection was conducted from May 10th to Jun 6th, 2020.

\section{Data Analysis}

To answer the research questions of this study, all participants' responses were coded and entered into IBM SPSS software (2020) (SPSS Inc., Chicago, IL, USA). Due to the categorical nature of the variables, Chi-square was used to examine participants' psychological symptoms and coping strategies based on their demographic characteristics (gender, age, field of study, academic year, type of studying program (graduate or undergraduate), the origin of student (national or international), and status of living (with family or without). $P$-values were then extracted for each demographic variable, where $p<0.01$ was considered statistically significant.

\section{Results}

\section{The Psychological Symptoms the Students Experienced during the Quarantine}

\section{Short Temper, Anxiety, and Depression Were the most Prevalent Psychological Symptoms among University Students during the Curfew}

The common psychological symptoms among students were anxiety, sleep problems, depression, short temper, low selfesteem, feeling helpless, feeling worthless, feeling unhappy, and focusing problems (Fig. 1). Short temper is the distress symptom most of the students experienced during the quarantine.

\section{Female Students Expressed more Psychological Symptoms than Males}

The analysis of students' psychological symptoms according to gender showed a significant difference $(p$ value $<0.01$ )
Fig. 1 The psychological symptoms the students experienced during the quarantine

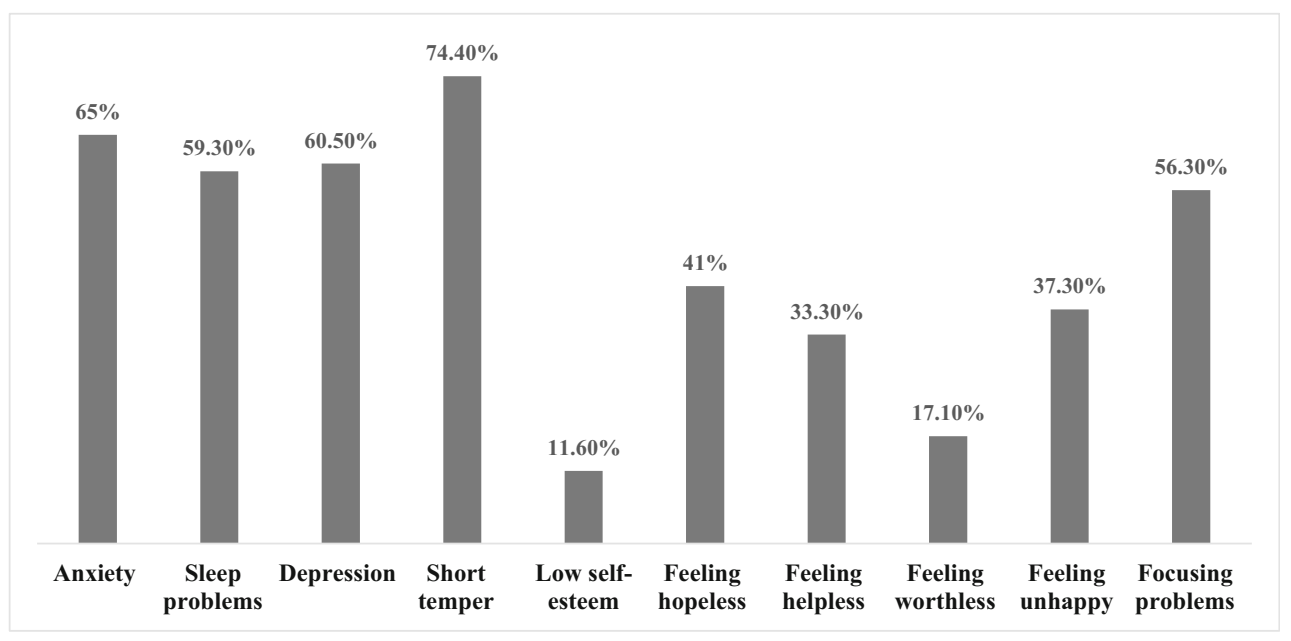


between male and female participants (Table 1) (Supplementary data Table 1 for details). Short temper, anxiety, sleep problems, and depression were the major psychological symptoms experienced by female students during the quarantine (Table 1).

\section{The Students' Age Correlated with the Expressed Psychological Symptoms}

Results showed a significant correlation $(P$ value $<0.01)$ between the students' age and the expressed psychological symptom. We found that students of different age categories expressed different kinds of psychological symptoms. Young students (18-20 years) expressed low self-esteem, hopelessness, helplessness, worthlessness, unhappy feelings, in

Table 1 The correlation of the psychological symptoms with the students' demographic information

\begin{tabular}{|c|c|c|c|c|}
\hline $\begin{array}{l}\text { Psychological } \\
\text { Symptoms }\end{array}$ & $\begin{array}{l}\text { Demographic } \\
\text { information }\end{array}$ & & $\begin{array}{l}\text { Chi } \\
\left(X^{2}\right)\end{array}$ & $\begin{array}{l}\mathrm{P} \text { - } \\
\text { value }\end{array}$ \\
\hline & Gender & Male & 31 & $0.001 *$ \\
\hline & & Female & & \\
\hline Anxiety & Age (Years) & $18-20$ & 66.6 & $0.005 *$ \\
\hline $\begin{array}{l}\text { Sleep } \\
\text { problems }\end{array}$ & & $21-25$ & & \\
\hline Depression & & $26-30$ & & \\
\hline Short temper & & $31-35$ & & \\
\hline $\begin{array}{l}\text { Felling } \\
\text { hopeless- } \\
\text { ness }\end{array}$ & & above 36 & & \\
\hline $\begin{array}{l}\text { Felling } \\
\text { helpless- } \\
\text { ness }\end{array}$ & Academic field & $\begin{array}{l}\text { Medical and } \\
\text { Pharmaceuti- } \\
\text { cal sciences }\end{array}$ & 35 & 0.7 \\
\hline $\begin{array}{l}\text { Feeling } \\
\text { worthless }\end{array}$ & & Engineering & & \\
\hline $\begin{array}{l}\text { Feeling } \\
\text { unhappy }\end{array}$ & & Science & & \\
\hline \multirow[t]{13}{*}{$\begin{array}{l}\text { Focusing } \\
\text { problems }\end{array}$} & & $\begin{array}{l}\text { Literacy and } \\
\text { humanities }\end{array}$ & & \\
\hline & \multirow[t]{6}{*}{ Academic year } & First & 67 & 0.05 \\
\hline & & Second & & \\
\hline & & Third & & \\
\hline & & Forth & & \\
\hline & & Fifth & & \\
\hline & & Sixth & & \\
\hline & \multirow[t]{2}{*}{ Academic program } & Graduate & 3.5 & 0.96 \\
\hline & & Undergraduate & & \\
\hline & \multirow{2}{*}{$\begin{array}{l}\text { Studying status } \\
\quad \text { (international) }\end{array}$} & Yes & \multirow[t]{2}{*}{15} & \multirow[t]{2}{*}{0.13} \\
\hline & & No & & \\
\hline & \multirow{2}{*}{$\begin{array}{l}\text { Living status (Student } \\
\text { living away from } \\
\text { country and family) }\end{array}$} & Yes & \multirow[t]{2}{*}{9} & \multirow[t]{2}{*}{0.56} \\
\hline & & No & & \\
\hline
\end{tabular}

$* \mathrm{p}<0.01$ is considered significant addition to focusing problems. Students who were 2125 years old had mainly depression. Students above 30 years old had anxiety, sleep problems, and a short temper (Table 1) (Supplementary data Table 2 for details).

\section{The Students' Academic Field, Academic Year, Studying Program, Origin, and Living Status Did Not Affect the Experienced Psychological Symptoms during the Curfew}

Results on (Table 1) (supplementary data Tables 3, 4, 5, 6, and 7 for details) showed no significant difference between the displayed psychological symptom and students' academic field (Medical and Pharmaceutical, Engineering, Science, Literacy and Humanities), academic year (first, second, third, fourth, fifth, and sixth), studying program (graduate, undergraduate), the students' origin (national or international), or with students' living status (living away from family and country).

\section{The Coping Strategies the Students Practiced during the Quarantine}

\section{University' Students Spent Most of their Time during Quarantine in Studying and Sleeping}

The coping strategies were addressed in Fig. 2, They were; 1) studying, 2) working, 3) exercising, 4) playing video games, 5) worshiping (meditation), 6) sleeping, 7) watching COVID19 news and updates, 8) watching entertainment programs like (movies and series), 9) cooking, 10) house chores like cleaning and organizing, 11) helping their siblings or kids in studying and homework, and 12) volunteering in hospitals or seniors' houses. Most of the students spent their time during quarantine on studying, sleeping, worshipping, and meditation.

\section{The Students' Gender Significantly Correlated with Coping Strategies Practiced during the Quarantine}

In comparison to male students, female students spent most of their time during the quarantine sleeping, studying, worshiping, cooking, and helping their siblings/children in studying (Table 2) (Supplementary data Table 1 for details). Whereas male students were mainly working or focused on electronicsbased activities such as; playing video games, watching COVID-19 news, watching entertaining programs like movies and series (Table 2).

\section{The Students' Coping Strategies Tuned in with their Age Categories}

The results presented in the Table 2 showed a significant correlation $(P$ value $<0.01)$ between the students' academic year 


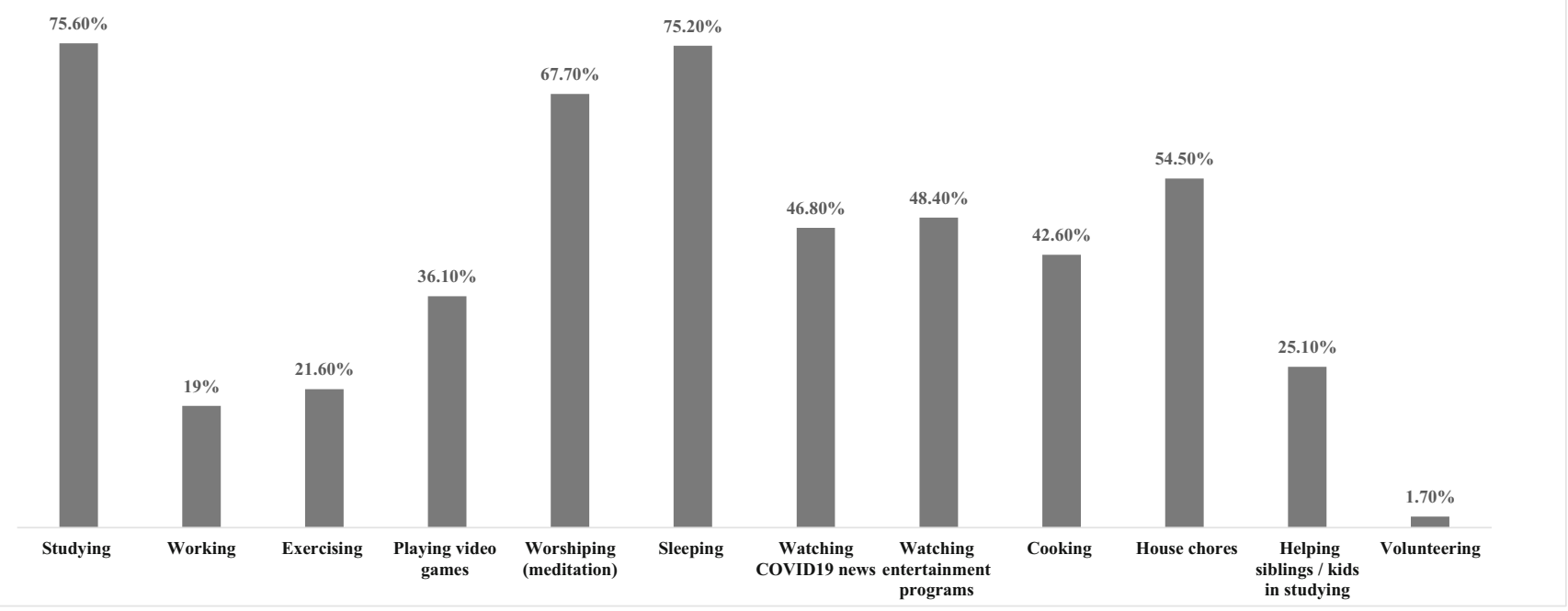

Fig. 2 The coping strategies the students practiced during the quarantine

and the adopted coping strategy (Supplementary data Table 2 for details). Younger students (18-25 years old) spent most of their time during the quarantine on sleeping, playing video games, or watching entertaining programs. Whereas elder students (above 30 years old) focused on studying, exercising, worshiping, cooking, and watching COVID-19 news.

\section{The Students' Academic Field Affected their Coping Strategies}

The students' coping strategies were significantly ( $\mathrm{P}$ value $<0.01$ ) correlated with students' academic field (Medical and Pharmaceutical Sciences, Engineering, Science, Literacy, and Humanities) (Table 2) (Supplementary data Table 3 for details). Medical and Pharmaceutical science' students spent most of their time studying, sleeping, house chores, or cooking. The Engineering students focused on studying, working, exercising, and playing video games. Science students focused on worshiping and sleeping. Literacy and Humanities students advocated watching COVID-19 news and entertaining programs like videos and movies (Table 2).

\section{The Students' Coping Strategies Varied According to their Academic Year}

Results in Table 2 showed that the students' coping strategies were significantly $(P$ value $<0.01)$ correlated with the students' academic year (first, second, third, fourth, fifth, and sixth). The first and second-year students were playing video games, worshiping, sleeping, and watching COVID-19 news. The third-year students were interested in watching entertaining programs. The fourth and the fifth-year students focused on studying, working, exercising, and doing house chores (Supplementary data Table 4 for details).

\section{The Students' Academic Program Influenced their Coping Strategies}

Results showed a significant correlation $(P$ value $<0.01)$ between students' academic programs and coping strategies (Table 2) (Supplementary data Table 5 for details). Graduate students were more focused on studying, watching COVID19 news, cooking, and house chores. While undergraduates leaned towards exercising, playing video games, watching entertaining programs, and helping their siblings in studying.

\section{The Students' Origin (National or International) Affected their Coping Strategies}

More than 44,000 international students were studying in Jordan (Ministry of Higher Education \& Scientific Research, n.d.-a), we wondered if the student' origin would affect their coping strategies. Results showed a significant $(P$ value $<0.01)$ link between the student origin and the coping strategy (Table 2) (Supplementary data Table 6 for details). In comparison to national students, the international students' focus was on studying, exercising, watching entertaining programs, and cooking respectively.

\section{The Students' Living Status (Living with or without Family) Impacted their Coping Strategies}

Around $40 \%$ of students were not living with their families during the quarantine (methods section, population, and samples). We wondered if the students' living status would affect their coping strategies. Results showed a significant ( $\mathrm{P}$ value $<0.01$ ) correlation between the students' living status and the coping strategies (Table 2) (Supplementary data Table 7 for details). Students who were living away from their families 
Table 2 The correlation of the coping strategies with the students' demographic information

\begin{tabular}{lllll}
\hline $\begin{array}{l}\text { Coping } \\
\text { Strategies }\end{array}$ & $\begin{array}{l}\text { Demographic } \\
\text { information }\end{array}$ & & Chi & $\begin{array}{l}\text { P - } \\
\left(X^{2}\right)\end{array}$ \\
value
\end{tabular}

$* \mathrm{p}<0.01$ is considered significant

coped by playing video games, watching entertaining programs, and cooking.

\section{Discussion}

The findings of this study showed that female students expressed more psychological symptoms than males, they managed their stress by sleeping, studying, and worshiping. While male students were working, exercising, and playing video games. We also found that young students expressed unhappiness and distress-like symptoms and they advocated sleeping and playing video games, whereas elder students had anxiety, sleep problems, and short tempers, they managed their symptoms by studying, exercising, and worshiping. Of note, the curfew restrictions have negatively impacted the mental health of female and younger students the most. During the curfew, students had to stay at home and switch to online learning platform, socially isolated, surrounded by fear, worries, and uncertainty. Consequently, distress and mood symptoms are compounded in susceptible students, while the resilient students found strategies to cope with the unprecedented situations.

Herein, we discussed students' mental health during the military enforced quarantine. The first research question was answered by addressing the psychological symptoms the university students experienced during the curfew. The emphasis of research on students' mental health and wellbeing during the pandemic is a necessity. Cao et al. discussed the effect of the pressure created from the fear of infection and death on college students. They found that most of the students suffered from different degrees of anxiety, which were strengthened or weakened depending on other factors like income stability, living status, or living in urban areas (Cao et al., 2020). The students' mental health and behavior of college students during the early phases of the COVID-19 pandemic was also discussed by Huckins et al. They found a significant association between the COVID-19 news and the increase in depression and anxiety among college students (Huckins et al., 2020a). A previous study by Naser et al. was performed in Jordan, they found that the prevalence of anxiety was higher among the university students as compared to the rest of the population (Naser et al., 2020). In concordance with the previous studies, we found that short temper, anxiety, and depression were the most prevalent psychological symptoms (> $60 \%$ ) among university students in Jordan.

The third research question was approached by addressing the coping strategies the students practiced during the quarantine. The students spent most of their time studying, concomitant with the online learning platform that was followed by all institutions in Jordan during the quarantine (Ala'a B. AlTammemi, 2020). Besides, the students reported that they spent their time during the quarantine in sleeping. It was not within the scope of this study to investigate differences in sleep patterns during quarantine to conduct a comparison with pre-pandemic sleep preferences. So it was difficult to differentiate between the normal recommended sleeping hours that help students to reduce tension, regulates mood, improves concentration and memory (Carley \& Farabi, 2016), and oversleeping that had negative health impacts on students, like cognitive impairment, depression, risk of obesity, diabetes, and heart diseases (Quan et al., 2018).

The rest of the research questions were answered by emphasizing the correlations between the students' sociodemographics like gender and age, and the expressed psychological symptoms and coping strategies. Few studies 
discussed the effect of COVID-19 quarantine on the mental health of different genders. They found that young women expressed more distress-related symptoms than men (Rossi et al., 2020b; Qiu et al., 2020). Men and women handle stress differently, women tend to use their emotional responses to stressful situations, whereas men use problem-focused and instrumental methods to deal with stressful experiences (Endler \& Parker, 1990; Kelly et al., 2008). We found that female students were more susceptible to the psychological distress symptoms like short-temper, anxiety, depression, and insomnia than males. They spent their time mainly sleeping, studying, worshiping, cooking, and helping their siblings/kids in studying. Whereas male students focused on working, exercising, using electronics, and playing video games. Implying that women are more susceptible to depression than men, this could be due to their emotional nature and to the physiological changes during the reproductive period (sex hormones level and immune functions) (Matud, 2004). So, women are considered among the vulnerable groups who need more assistance during the pandemic.

We also discussed the correlation of students' age with the expressed psychological symptoms and coping strategies during the quarantine. In a comparison Aldwin et al. studied different aged people (18-89 years), and found that individuals of different ages expressed different degrees of stress, and they had distinct coping strategies. Younger adults tended to use problem-focused coping strategies more than older adults (Aldwin et al., 1996a). Another study discussed the influence of age on stress management, the participants were university students (18-29 years), they found that older students used problem- solving, and cognitive restructuring as coping strategies more than younger students (Monteiro et al., 2014). Our results confirmed the previous findings. We found that young students (18-25 years) expressed unhappiness distress-like symptoms; for example, low self-esteem, hopelessness, helplessness, worthlessness, and depression. They coped by spending their time sleeping, playing video games, and watching entertaining programs. While elder students (> 26 years) had anxiety, sleep problem, and short temper, they coped by focusing on studying, exercising, worshiping, cooking, and watching COVID-19 news. Our findings indicated that young students were more likely to suffer from distress symptoms during the quarantine than elder students. It could be because young students were not emotionally mature enough to mitigate the distress feelings they experienced during the quarantine. They spent a lot of time on electronics and social media following the COVID-19 news updates, which may negatively affect their moods and feelings (Aldwin et al., 1996b; Ala'a B. Al-Tammemi et al., 2020).

The link between the students' academic field and stress was previously discussed (May \& Casazza, 2012; Elias et al., 2011). Unlike the previous findings, we found that students' study major didn't influence their expressed psychological symptoms. This could be due to the low sample size and the unequal number of students of each major. On the other hand, we found that students' major affected their coping strategies. Students of scientific majors like; health sciences and engineering spent their time studying and working, whereas literacy students were interested in sleeping, worshiping, and playing video games. This could be related to the difference in academic majors, in general, scientific majors need hard work and long studying hours compared to literacy and humanity majors.

We opt to study the quarantine effect on the international students and on students who lived away from their families. In Jordan, around $14 \%$ of the university students were international students (Ministry of Higher Education \& Scientific Research, n.d.-b), so it is worthwhile to investigate the pandemic effect on this student category. A study by Cao et al. showed that living with families during the pandemic reduced the negative effect of the quarantine on students (Cao et al., 2020). Nevertheless, we found no significant difference in the expressed psychological symptoms between national and international students, or between students who lived alone or with families during the pandemic. This could be due to the sample size difference between the two categories.

Watching entertaining programs, playing video games, and cooking were the most common activities for the international students and the students who lived away from their families (Baloran, 2020; Ala'a B. Al-Tammemi et al., 2020).

Worshiping and meditation were among the positive coping strategies practiced by students during the quarantine. These strategies foster a good connection with the creator, and they provide a calming power on body and soul (Baloran, 2020; Polizzi et al., 2020). This in turn may help students to cope with the quarantine negative effects.

\section{Limitations}

Several limitations may impact the generalizability of the findings reported in this study. Perhaps, one of the most serious limitations is the lack of knowledge about our respondents' previous or existing mental health issues like suffering from SPD, which affected their perception and rationale (Serafini et al., 2017), or the sort of treatment that they were receiving before the pandemic. Additionally, our survey is lacking comparison to a typical semester unaffected by the pandemic, or a different time point of the year. The synchronization of quarantine with online learning affected the students' mental health. Depression and anxiety levels spiked when the campus switched to remote learning but decreased in the following weeks (Huckins et al., 2020b). Therefore, it is important to keep monitoring the change to better understand the long-term effect of the pandemic on university students' mental health. Furthermore, the nature of our cross-sectional design limits us 
from establishing a causal relationship between psychological impacts and students' coping strategies they used. Therefore, a prospective longitudinal design and experimental studies are needed to demonstrate causality. The data in this study mostly came from students who study health and engineering sciences; thus, the present results are likely difficult to generalize to other literature and humanities fields of study. Moreover, we found that undergraduate students have been more impacted during the pandemic compared to graduate students, probably from adapting to distance learning, which makes it difficult to generalize the finding of this study to a wide classification of university students. Yet the reported factors need further investigation in the coming future. An interventional study on students' mental health counseling and peer support used to mitigate the pandemic negative impacts could also be important to help university students relieve from the negative impacts of the quarantine.

\section{Implications}

The study suggests that universities' mental health service needs to provide different kinds of support to vulnerable groups like female, young, and international students. Students need to be guided towards healthy coping strategies to mitigate their stresses such as exercising and meditation, and to avoid unhealthy behaviors like; smoking and playing video games.

Universities can also implement suitable online remote activities and services to provide support to students that help address concerns related to the pandemic. For example, Schlesselman et al provided a list of activities that can potentially support students in fitness, socialization, and academic success (e.g., virtual group exercise, virtual movie night, and virtual office hours (Schlesselman et al., 2020). However, there is no one-size-fits-all solution. More exploration is needed to identify the appropriate ways to implement such support and assess the long-term effects of such interventions.

At a governance level, the Ministry of Higher Education (MoHE), which governs Higher Education Institutions (HEIs) in the country, can play an important role in guiding universities to address the mental health issues of their students. An example of such guidance is encouraging HEIs to take appropriate actions to ensure mental health supports and resources are available to students as needed. This could include augmenting existing mental health services available in each institution. Furthermore, the ministry could emphasize that mental health and wellbeing support should be made accessible for diverse groups (e.g., considerations based on factors such as gender, geographic location, rurality, ability, age, socioeconomic status, and other intersecting identities). Additionally, as the management of COVID-19 moves away from the initial response and mitigation phases, the time to strengthen the collaboration and synergy between MoHE, and HEIs, both locally and internationally, is urgently needed. This recognizes that a serious problem like, COVID-19 pandemic that may last for years, cannot be "solved" in the way that the initial policy responses appeared at the beginning of the pandemic. Instead, those governing bodies need to learn to "live with and manage the impacts of crises that are wicked and unsolvable" (Hartley et al., 2019). Both governments and ministries of higher education around the world need to support HEIs and encourage funds to collectively develop and share good practices towards improving students' mental health.

\section{Conclusions}

The military enforced curfew practiced in Jordan during the COVID-19 pandemic protected people from infection and prevented the disease widespread. However, it negatively impacted the university students' mental health. Our study spotlights on the most common psychological symptoms the students experienced during the pandemic and the coping strategies they practiced to mitigate the pandemic effect. These research outcomes will add to previous knowledge about the pandemic psychological effects on students' mental health. It will also highlight the healthy coping strategies the students need to follow to mitigate the quarantine related stress. The study findings are expected to help decision-makers in the ministries of education and higher education locally and globally, to understand students' attitudes and motivations toward learning during the pandemics, and to implement healthy coping strategies to be followed by students' mental health services in universities during the pandemics.

Supplementary Information The online version contains supplementary material available at https://doi.org/10.1007/s12144-021-01833-1.

Authors' Contributions EA: the survey idea, format, and design, and writing the manuscript. AQ: Study design and data analysis, FA and AA participated in the study design and writing the manuscript.

Data Availability The datasets used or analyzed or generated in this study are included in the manuscript. The raw data supporting the conclusions of the article is available in the following link: (https://docs.google.com/ spreadsheets/d/1lrN2Pc pxaBsOUOt2JyxTeo1wFfWDjZs8-J3B6HtF8/ edit?usp=sharing). The survey is available in the following link: (https:// $\mathrm{d}$ o c s . g o o g l e . c o m/for m s / d / 1O0yWzKQ3e5rVM64pKuLBCmjeJiABH8j6sbwEutsjCgk/edit).

\section{Declarations}


Ethics Approval The studies involving human participants were reviewed and approved by the Institutional Review Board (IRB) committee of the Alzaytoonah University of Jordan. This study was approved by the IRB with no need for written consent for students' participation.

Declaration of Interest No potential conflict of interest was reported by the authors

Supplementary Information The online version contains supplementary material available at https://doi.org/10.1007/s12144-021-01833-1.

\section{References}

Advice for the public. (n.d.). Retrieved February 4, 2021, from https:// www.who.int/emergencies/diseases/novel-coronavirus-2019/ advice-for-public.

Aldwin, C. M., Sutton, K. J., Chiara, G., \& Spiro, A. (1996a). Age differences in stress, coping, and appraisal: Findings from the normative aging study. The Journals of Gerontology Series B: Psychological Sciences and Social Sciences, 51B(4), P179-P188. https://doi.org/10.1093/geronb/51B.4.P179.

Aldwin, C., Sutton, K., Chiara, G., \& Spiro, A. (1996b). Age differences in stress, coping, and appraisal: Findings from the normative aging study. The Journals of Gerontology. Series B Psychological Sciences and Social Sciences, 51, P179-P188. https://doi.org/10. 1093/geronb/51B.4.P179.

Almomani, E. Y., Qablan, A. M., Atrooz, F. Y., Almomany, A. M., Hajjo, R. M., \& Almomani, H. Y. (2021). The influence of coronavirus diseases 2019 (COVID-19) pandemic and the quarantine practices on university students' beliefs about the online learning experience in Jordan. Frontiers in Public Health, 8, 8. https://doi.org/10. 3389/fpubh.2020.595874.

Al-Tammemi, A.'a. B. (2020). The Battle against COVID-19 in Jordan: An early overview of the Jordanian experience. Frontiers in Public Health, 8. https://doi.org/10.3389/fpubh.2020.00188.

Al-Tammemi, A.'a. B., Akour, A., \& Alfalah, L. (2020). Is It Just About Physical Health? An Online Cross-Sectional Study Exploring the Psychological Distress Among University Students in Jordan in the Midst of COVID-19 Pandemic. Frontiers in Psychology, 11. https://doi.org/10.3389/fpsyg.2020.562213.

Amerio, A., Bianchi, D., Santi, F., Costantini, L., Odone, A., Signorelli, C., Costanza, A., Serafini, G., Amore, M., \& Aguglia, A. (2020). Covid-19 pandemic impact on mental health: A web-based crosssectional survey on a sample of Italian general practitioners. Acta Biomedica Atenei Parmensis, 91(2), 83-88. https://doi.org/10. 23750/abm.v91i2.9619.

Baloran, E. T. (2020). Knowledge, attitudes, anxiety, and coping strategies of students during COVID-19 pandemic. Journal of Loss and Trauma, O(0), 1-8. https://doi.org/10.1080/15325024.2020. 1769300, 25.

Cao, W., Fang, Z., Hou, G., Han, M., Xu, X., Dong, J., \& Zheng, J. (2020). The psychological impact of the COVID-19 epidemic on college students in China. Psychiatry Research, 287, 112934. https://doi.org/10.1016/j.psychres.2020.112934.

Carley, D. W., \& Farabi, S. S. (2016). Physiology of sleep. Diabetes Spectrum, 29(1), 5-9. https://doi.org/10.2337/diaspect.29.1.5.

CDC. (2020). Coronavirus disease 2019 (COVID-19). Centers for Disease Control and Prevention. https://www.cdc.gov/coronavirus/ 2019-ncov/daily-life-coping/managing-stress-anxiety.html

COVID-19 pandemic in Jordan. (2020). In Wikipedia. https://en. wikipedia.org/w/index.php?title=COVID-19_pandemic_in Jordan\&oldid $=968968590$
Elias, H., Ping, W. S., \& Abdullah, M. C. (2011). Stress and academic achievement among undergraduate students in Universiti Putra Malaysia. Procedia - Social and Behavioral Sciences, 29, 646655. https://doi.org/10.1016/j.sbspro.2011.11.288.

Endler, N. S., \& Parker, J. D. (1990). Multidimensional assessment of coping: A critical evaluation. Journal of Personality and Social Psychology, 58(5), 844-854. https://doi.org/10.1037/0022-3514. 58.5.844.

Haider, A., \& Al-Salman, S. (2020). Dataset of Jordanian University students' psychological health impacted by using E-learning tools during COVID-19. Data in Brief, 32, 106104. https://doi.org/10. 1016/j.dib.2020.106104.

Hartley, K., Kuecker, G., \& Woo, J. J. (2019). Practicing public policy in an age of disruption. Policy Design and Practice, 2(2), 163-181. https://doi.org/10.1080/25741292.2019.1622276.

Huckins, J. F., daSilva, A. W., Wang, W., Hedlund, E., Rogers, C., Nepal, S. K., Wu, J., Obuchi, M., Murphy, E. I., Meyer, M. L., Wagner, D. D., Holtzheimer, P. E., \& Campbell, A. T. (2020a). Mental health and behavior of college students during the early phases of the COVID-19 pandemic: Longitudinal smartphone and ecological momentary assessment study. Journal of Medical Internet Research, 22(6), e20185. https://doi.org/10.2196/20185.

Huckins, J. F., DaSilva, A. W., Wang, W., Hedlund, E., Rogers, C., Nepal, S. K., Wu, J., Obuchi, M., Murphy, E. I., Meyer, M. L., Wagner, D. D., Holtzheimer, P. E., \& Campbell, A. T. (2020b). Mental health and behavior of college students during the early phases of the COVID-19 pandemic: Longitudinal smartphone and ecological momentary assessment study. Journal of Medical Internet Research, 22(6), e20185. https://doi.org/10.2196/20185.

Kelly, M. M., Tyrka, A. R., Price, L. H., \& Carpenter, L. L. (2008). Sex differences in the use of coping strategies: Predictors of anxiety and depressive symptoms. Depression and Anxiety, 25(10), 839-846. https://doi.org/10.1002/da.20341.

Li, D. K. T., \& Zhu, S. (2020). Contributions and challenges of general practitioners in China fighting against the novel coronavirus crisis. Family Medicine and Community Health, 8(2), e000361. https://doi. org/10.1136/fmch-2020-000361.

Li, Q., Guan, X., Wu, P., Wang, X., Zhou, L., Tong, Y., Ren, R., Leung, K. S. M., Lau, E. H. Y., Wong, J. Y., Xing, X., Xiang, N., Wu, Y., Li, C., Chen, Q., Li, D., Liu, T., Zhao, J., Liu, M., Tu, W., Chen, C., Jin, L., Yang, R., Wang, Q., Zhou, S., Wang, R., Liu, H., Luo, Y., Liu, Y., Shao, G., Li, H., Tao, Z., Yang, Y., Deng, Z., Liu, B., Ma, Z., Zhang, Y., Shi, G., Lam, T. T. Y., Wu, J. T., Gao, G. F., Cowling, B. J., Yang, B., Leung, G. M., \& Feng, Z. (2020). Early transmission dynamics in Wuhan, China, of novel coronavirusinfected pneumonia. New England Journal of Medicine, 382(13), 1199-1207. https://doi.org/10.1056/NEJMoa2001316.

Matud, M. (2004). Gender differences in stress and coping styles. Personality and Individual Differences, 37, 1401-1415. https://doi. org/10.1016/j.paid.2004.01.010.

May, R., \& Casazza, S. P. (2012). Academic major as a perceived stress indicator: Extending stress management intervention. College Student Journal, 46, 264-273.

Ministry of Health, the official website of the Jordanian Ministry of Health | Coronavirus disease. (n.d.). Retrieved December 27, 2020, from https://corona.moh.gov.jo/en

Ministry of Higher Education \& Scientific Research. (n.d.-a). Retrieved September 12, 2020, from http://www.mohe.gov.jo/en/Pages/ default.aspx/FAQs.aspx

Ministry of Higher Education \& Scientific Research. (n.d.-b). Retrieved September 15, 2020, from http://www.mohe.gov.jo/en/Pages/ default.aspx/FAQs.aspx

Monteiro, N. M., Balogun, S. K., \& Oratile, K. N. (2014). Managing stress: The influence of gender, age and emotion regulation on coping among university students in Botswana. International Journal of 
Adolescence and Youth, 19(2), 153-173. https://doi.org/10.1080/ 02673843.2014 .908784

Naser, A. Y., Dahmash, E. Z., Al-Rousan, R., Alwafi, H., Alrawashdeh, H. M., Ghoul, I., Abidine, A., Bokhary, M. A., AL-Hadithi, H. T., Ali, D., Abuthawabeh, R., Abdelwahab, G. M., Alhartani, Y. J., Muhaisen, H. A., Dagash, A., \& Alyami, H. S. (2020). Mental health status of the general population, healthcare professionals, and university students during 2019 coronavirus disease outbreak in Jordan: A cross-sectional study. Brain and Behavior, 10(8), e01730. https://doi.org/10.1002/brb3.1730.

Polizzi, C., Lynn, S., \& Perry, A. (2020). Stress and coping in the time of COVID-19: Pathways to resilience and recovery. Clinical Neuropsychiatry, 17, 59-62.

Qiu, J., Shen, B., Zhao, M., Wang, Z., Xie, B., \& Xu, Y. (2020). A nationwide survey of psychological distress among Chinese people in the COVID-19 epidemic: Implications and policy recommendations. General Psychiatry, 33(2). https://doi.org/10.1136/gpsych2020-100213.

Quan, S. F., Combs, D., \& Parthasarathy, S. (2018). Impact of sleep duration and weekend oversleep on body weight and blood pressure in adolescents. Southwest Journal of Pulmonary \& Critical Care, 16(1), 31-41. https://doi.org/10.13175/swjpcc150-17.

Rossi, R., Socci, V., Talevi, D., Mensi, S., Niolu, C., Pacitti, F., Di Marco, A., Rossi, A., Siracusano, A., \& Di Lorenzo, G. (2020a). COVID-19 pandemic and lockdown measures impact on mental health among the general population in Italy. Frontiers in Psychiatry, 11. https:// doi.org/10.3389/fpsyt.2020.00790.
Rossi, R., Socci, V., Talevi, D., Mensi, S., Niolu, C., Pacitti, F., Di Marco, A., Rossi, A., Siracusano, A., \& Di Lorenzo, G. (2020b). COVID19 pandemic and lockdown measures impact on mental health among the general population in Italy. Frontiers in Psychiatry, 11. https://doi.org/10.3389/fpsyt.2020.00790.

Schlesselman, L. S., Cain, J., \& DiVall, M. (2020). Improving and restoring the well-being and resilience of pharmacy students during a pandemic. American Journal of Pharmaceutical Education, 84(6), ajpe8144. https://doi.org/10.5688/ajpe8144.

Serafini, G., Gonda, X., Canepa, G., Pompili, M., Rihmer, Z., Amore, M., \& Engel-Yeger, B. (2017). Extreme sensory processing patterns show a complex association with depression, and impulsivity, alexithymia, and hopelessness. Journal of Affective Disorders, 210, 249-257. https://doi.org/10.1016/j.jad.2016.12.019.

Sperber, A., DeVellis, R., \& Boehlecke, B. (1994). Cross-Cultural Translation. Journal of Cross-Cultural Psychology, 25, 501-524. https://doi.org/10.1177/0022022194254006.

Sundarasen, S., Chinna, K., Kamaludin, K., Nurunnabi, M., Baloch, G. M., Khoshaim, H. B., Hossain, S. F. A., \& Sukayt, A. (2020). Psychological impact of COVID-19 and lockdown among university students in Malaysia: Implications and policy recommendations. International Journal of Environmental Research and Public Health, 17(17), 6206. https://doi.org/10.3390/ijerph17176206.

Publisher's Note Springer Nature remains neutral with regard to jurisdictional claims in published maps and institutional affiliations. 